integrated teams of health professionals who provide and coordinate care within a patientcentered model.

2. PAEA/STFM recommend the development and integration of new interprofessional curricula for medical and PA students and family medicine residents.

3. PAEA/STFM recommend that medical schools, PA programs, and family medicine residencies expand the use of interprofessional clinical sites for students and residents, where they will learn how to efficiently and effectively provide patient-centered, team-based care as members of future patient-centered medical homes.

4. PAEA/STFM encourage the development of federal and private funding sources from family medicine and PA programs to create innovative interprofessional curricula that would result in expansion and increased effectiveness of patientcentered medical homes.

5. PAEA/STFM encourage collaboration with other health professions and disciplines to expand the scope of interprofessional team education and practice.

"The members of the PAEA/STFM Joint Position Paper workgroup valued collaboration and understood our professions' interconnected history and shared vision for team training of future primary care clinicians. They worked hard to create a paper that reflects these concepts and to help frame the discussion for future collaboration between our 2 disciplines," said Dave Keahey, MSPH, PA-C, chair of the Joint Paper Workgroup. Other members of the workgroup included: Perry Dickinson, MD; Karen Hills, MS, PA-C; Victoria Kaprielian, MD; Kevin Lohenry, PhD, PA-C; Gail Marion, PhD, PA-C; Traci Nolte, CAE; Michel Statler, MLA, PA-C; and Anne Walsh, PA-C, MMSc.

"When professions focus on their common ground-common interests, common mission, and common vision - it results in shared commitment. For STFM and PAEA, our commitment is to jointly evolve education in the name of our patients, looking at new educational models in the PCMH, clinical education, and in the classroom," said Timi Barwick, PAEA executive director. "Our work is just beginning."

Traci Nolte, CAE

Director of Publications and Community Society of Teachers of Family Medicine

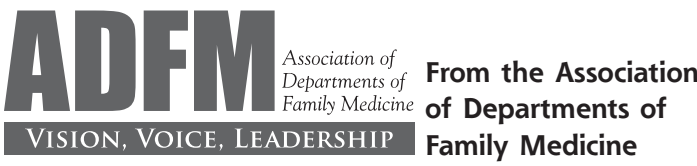

Ann Fam Med 2012;10:471-472. doi:10.1370/afm.1439.

\section{ADFM'S MISSION, VISION, AND GOALS: FOUNDATION OF OUR NEW 3-YEAR STRATEGIC PLAN}

Two years ago, with the passage of the Affordable Care Act, the leadership of ADFM began to think strategically about the direction for our organization during these unprecedented times. The new health care reform contained specific programs to enhance payment for primary care services, promote development of medical homes, expand use of health care technology, fuel growth of community health centers and FQHCs, and promote delivery of preventive services as well as many other important changes. We recognized that new payment mechanisms would emerge both from federal health reform and from elective evolution of the commercial market. Virtually every one of these new ideas relied then, and continues to rely now, on the availability of high functioning primary care, far in excess of existing primary care services.

As we considered how to take advantage of the many opportunities while maintaining our fundamental goal to serve departments of family medicine, the ADFM Executive Committee, in consultation with the Board of Directors, identified 5 challenges facing ADFM: (1) managing the growth of ADFM including the increasing complexity of membership involving both chairs and administrators of departments of family medicine; (2) diversifying our services to help both chairs and administrators perform their jobs more effectively $_{i}$ (3) growing our very limited resources; (4) focusing our work to have maximal influence during this unprecedented time; and (5) maximizing our collaborative relationships within and outside family medicine to help create a better future.

Two priorities emerged for ADFM as the leadership and board considered how to address these challenges: (1) to help departments of family medicine do a better job and $_{i}$ (2) to impact the external environment in a way that leverages our departments' skill sets, expertise, and competencies to improve public health. In November 2010, we engaged our members to carefully consider how best to organize ADFM to address these priorities. These critical conversations confirmed the importance of maintaining both the strength of our winter meeting and our advocacy col- 
laboration with other academic family medicine organizations. Also emerging from these discussions was the need for focused work in 4 areas: (1) developing leaders in departments of family medicine ${ }_{i}(2)$ transforming education; (3) transforming health care delivery; and (4) developing research capacity. Four new strategic committees aligned with these areas, each with defined membership, expectations, and accountability to the board, were formed in 2011 and quickly took on focused activities.

All of this momentum galvanizing ADFM's focus in 2010 and 2011 led the Board to engage outside consultation in late 2011 to move us from strategic thinking to delineation of a complete 3 -year strategic plan to guide ADFM. The board of directors, with feedback from the membership of ADFM, has since approved the following mission, vision, and goals for ADFM in a new 3-year (2012-2015) Strategic Plan.

\section{ADFM Strategic Plan (2012-2015): Mission, Vision and Goals \\ Mission}

The Association of Departments of Family Medicine (ADFM) is the organization of departments of family medicine and is devoted to transforming care, education, and research to promote health equity and improve the health of the nation.

\section{Vision}

Departments of Family Medicine will lead transformation of medical education, research, and health care to improve the health of the nation.

\section{Goals}

Goal 1: Transform Health Care Delivery

Goal Statement: ADFM will assist departments in transforming the clinical delivery enterprise to advance the triple aim of higher quality, improved health and lower cost.

\section{Goal 2: Develop Leaders}

Goal Statement: ADFM will enhance the leadership skills of chairs, administrators and future department leaders to improve the effectiveness of DFMs.

\section{Goal 3: Strengthen Research}

Goal Statement: ADFM will assist DFMs to build research capacity and to strengthen the quality of their research.

\section{Goal 4: Transform Education}

Goal Statement: ADFM will assist departments to develop, implement and evaluate innovative models of education across the UME/GME/Faculty development continuum.
Goal 5: Develop ADFM Infrastructure/Governance Goal Statement: ADFM will create and maintain the appropriate staffing, governance and technological resources to support membership services and organizational effectiveness.

Four ADFM Committees and a board infrastructure/governance taskforce are working to flesh out specific objectives within each of the 5 goals over the coming months with anticipated approval of the full strategic plan by the time the ADFM Board convenes in November 2012.

ADFM is excited about the explicit guidance this new 3-year strategic plan provides to help our departments of family medicine and to collaborate with other leaders and organizations as we forge ahead to create a healthier future.

$$
\begin{array}{r}
\text { ADFM Executive Committee } \\
\text { Tom Campbell, MD, President } \\
\text { Richard Wender, MD, Board Chair, Past-President } \\
\text { Barbara Thompson, MD, President-elect } \\
\text { Ardis Davis, MSW, Executive Director }
\end{array}
$$

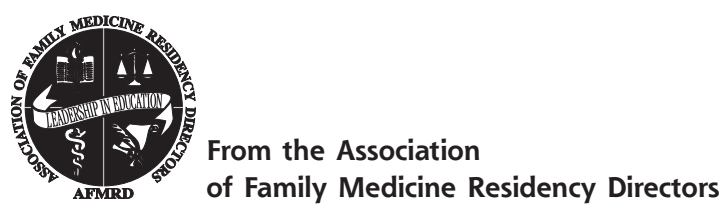

Ann Fam Med 2012;10:472-473. doi:10.1370/afm.1440.

\section{PRIMARY CARE PAYMENT REFORM: THE MISSING LINK}

Over the past several years as the patient-centered medical home (PCMH) has become a prominent feature in the design of family medicine in the future, we are seeing supportive data suggesting that this model has great potential to improve our health care system and lower cost of care. However, we've also had reports of the impact of implementing the $\mathrm{PCMH}$ model in various clinical settings with differing payment models. The basic summary of this information is that clinics operating with a fee-for-service model attempting to implement $\mathrm{PCMH}$ have very high rates of staff and physician burnout and are losing revenue for non-office visit encounters with patients, making the model unsustainable within the fee-for-service environment. Furthermore, systems where there is either primary care capitation or full capitation that support PCMH implementation are showing just the opposite-high provider satisfaction, patient satisfaction, and improved revenues to support the clinic operations. 